\title{
Numerical Simulation of the Electron Beam Welding and Post Welding Heat Treatment Coupling Process
}

https://doi.org/10.1515/htmp-2017-0053

Received April 11, 2017; accepted September 1, 2017

\begin{abstract}
In this article, the electron beam welding and post welding heat treatment (PWHT) coupling process of nickel alloy GH80A is carried out using ABAQUS software. The thermo-mechanical coupling (TMC) model is considered in the simulation. The simulation results obtained from finite element method (FEM) including thermal history, heat source sharp, residual stress and stress relaxation. The simulation objectives are analysis of thermal field and heat source sharp which is compared with experimental results. These results also can determine the heat affected zone and residual stress during welding and stress relaxation which is produced by the post welding heat treatment process.
\end{abstract}

Keywords: electron beam welding (EBW), GH80A, coupling process, post welding heat treatment (PWHT), residual stress, heat source

\section{Introduction}

Welding and heat treatment are important process in industry. In the electron beam welding (EBW), a concentrated electron beam with a high-power density is used to melts and joins metals. The welding operation is

*Corresponding author: Wang Qingyuan, Key Laboratory of Energy Engineering Safety Disaster Mechanics, Ministry of Education, Sichuan University, Chengdu, Sichuan, China, E-mail: wangqy@scu.edu.cn Zhang Hong, Key Laboratory of Energy Engineering Safety Disaster Mechanics, Ministry of Education, Sichuan University, Chengdu, Sichuan, China

Men Zhengxing, Mechanical and Electrical Engineering Department, Chengdu Aeronautic Polytechnic, Chengdu, Sichuan, China Li Jiukai, Failure Mechanics and Engineering Disaster Prevention and Mitigation Key Laboratory of Sichuan Province, College of Architecture and Environment, Sichuan University, Chengdu, Sichuan, China Liu Yongjie, Key Laboratory of Energy Engineering Safety Disaster Mechanics, Ministry of Education, Sichuan University, Chengdu, Sichuan, China; Failure Mechanics and Engineering Disaster Prevention and Mitigation Key Laboratory of Sichuan Province, College of Architecture and Environment, Sichuan University, Chengdu, Sichuan, China performed in a medium-pressure vacuum environment to avoid oxidation of the weld zone and deplete the electrons [1]. The fusion zone is smaller than for MIG/TIG-welding and the penetration depth is large. Usually, post welding heat treatment is chosen to stress relief tempering process. The principle is heating and furnace cooling. However, these processes can produce not good results, such as residual stress and deformation, which must be considered when designing and optimized the product and process. Traditional experience test can give limit help to understand and check the stress and deformation, and costly and time consuming are needed. Nowadays, due to development in computer hardware, finite element method has been used to predict and optimize stress and deformation for welding [2] and heat treatment [3] process. For example, Piotr Lacki and Konrad Adamus [4] carried out the electron beam welding simulation of 30HGSA steel tubes. Peng-Hsiang Chang and Tso-Liang Teng [5] simulated the residual stresses of butt-welded joints and compared with experimental results. Yang $\mathrm{X}$ et al. [6] successfully predicted the quenching process and stress of aluminum alloy using finite element method. Meanwhile, welding and heat treatment co upling process simulation has been considered, for example, D. Berglund et al. [7] carried out the welding and stress relief heat treatment coupling simulation.

However, there is no report available on the simulation of the EBW and PWHT coupling process for nickel alloy GH80A. Based on the time and cost considerations in industry, FEM is employed to solve these problems. Therefore, the main objectives of present study are to analyze and build the welding and post welding heat treatment coupling simulation model and simulate a butt joint of $14 \mathrm{~mm}$ thick GH80A plates using ABAQUS. After that, the simulation results including thermal history and heat source shape during welding are compared with experimental results, and residual stress and stress relaxation during post welding heat treatment are compared each other. The detailed technical process is presented, i. e. (1) describe the EBW and PWHT experimental equipment and process; (2) to analyze and choose the welding heat source models of EBW and the heat transfer 
model for welding and PWHT; (3) to analyze the mechanical model for welding and PWHT; (4) to build the numerical simulation welding and heat treatment coupling model; (5) to compare and discuss the results of welding and PWHT.

\section{EBW and heat treatment equipment}

In the article, welding experimental work was performed using EBW unit which is shown in Figure 1. There are three main components including vacuum pumps, electron beam gun and working chamber. The EBW experimental parameters are presented, i.e. (1) Accelerating voltage of $85 \mathrm{kV}$; (2) Beam current of $40 \mathrm{~mA}$; (3) Vacuum in working chamber of $8 \times 10^{-2} \mathrm{mBar}$; (4) Welding velocity of $1400 \mathrm{~mm} / \mathrm{min}$.

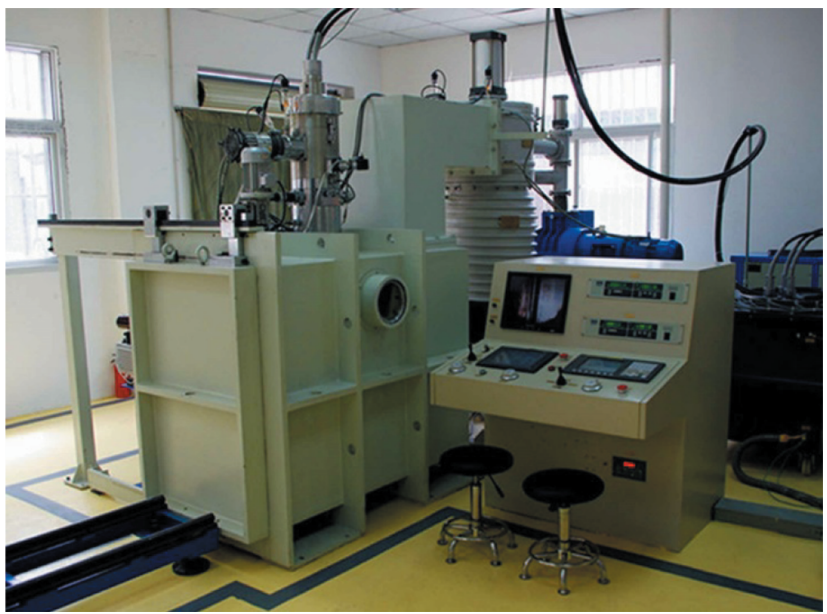

Figure 1: EBW equipment used in experiments.

The post weld heat treatment experimental work was performed using high temperature box resistance furnace. The heat treatment experimental curve is showed in Figure 2.

\section{Thermal phenomena}

\section{Welding heat source models}

In order to get the good numerical simulation results, accurate heat source models should be selected and used. In 1930s, point or line heat source models were developed by Rosenthal [8] and Rykalin [9]. However, this model is not accounting for the distribution of the

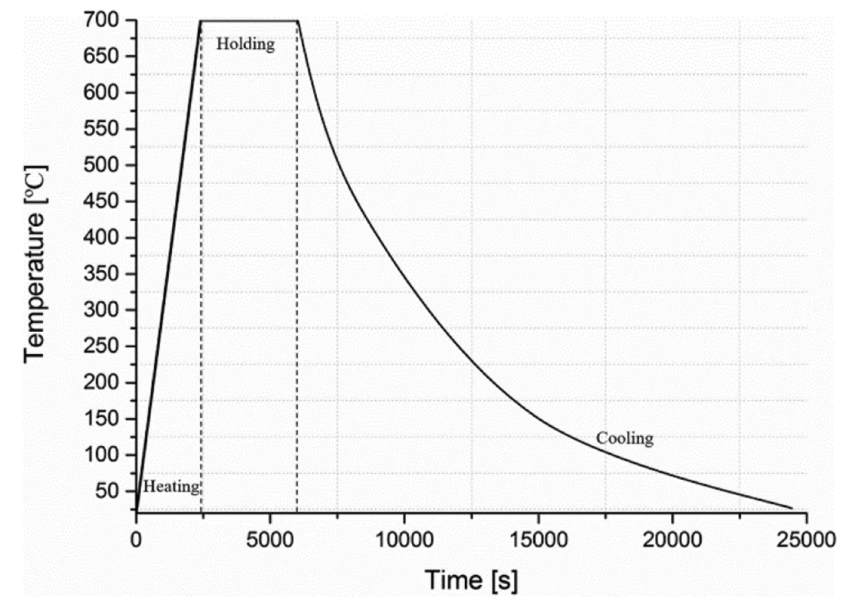

Figure 2: Thermal history during PWHT.

actual welding heat source. After that, Gaussian distribution heat source was suggested by the Pavelie et al. [10] firstly. In this model, the thermal flux has a Gaussian or normal distribution in the work plane, as shown in Figure 3:

$$
q(r)=q(0) e^{-C_{r}^{2}}
$$

where $q(r)$ is the surface flux of radius $r ; q(0)$ is maximum flux at the center of the heat source; $C$ is distribution coefficient; $r$ is the distance from the center of the heat source.

This heat source is more realistic than the point or line source because of the distribution over 2D surface

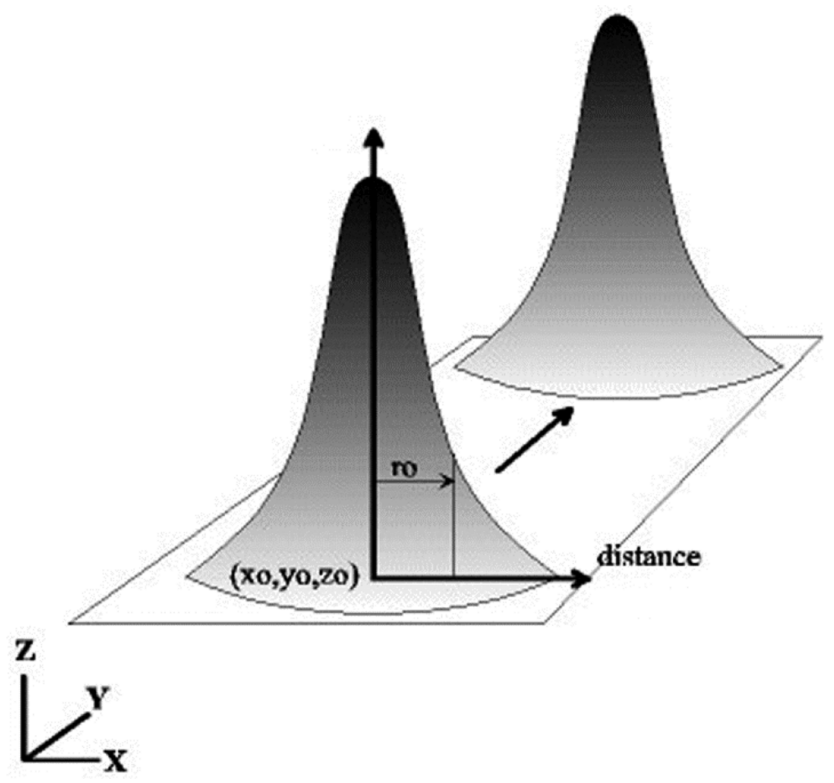

Figure 3: 2D Gaussian heat source. 
area. It is very useful to use this model preheat simulation under melting point. However, the depth of the weld pool is ignored in this heat source. The shape and size of weld pool is failed to consider. It is not possible to predict the deep penetration fusion zone of an electron beam or laser welding with the 2D Gaussian heat source [2].

The volume heat source defined by double ellipsoid was developed by GOLDAK J et al. [11], as shown in Figure 4 [12]. In this source, the fractions $f_{a_{r}}$ and $f_{a_{f}}$ of the heat distribution in the front and rear are defined, where $f_{a_{r}}+f_{a_{f}}=2$. This heat source is combined with two ellipsoidal sources. One is the front quadrant, which is described by the following function:

$$
q(x, y, z, t)=\frac{6 \sqrt{3} f_{f} Q}{a_{f} b c \pi \sqrt{\pi}} e^{-3 x^{2} / a_{f}^{2}} e^{-3 y^{2} / b^{2}} e^{-3[z+v(\tau-t)]^{2} / c^{2}}
$$

Another is the rear quadrant of the heat density distribution:

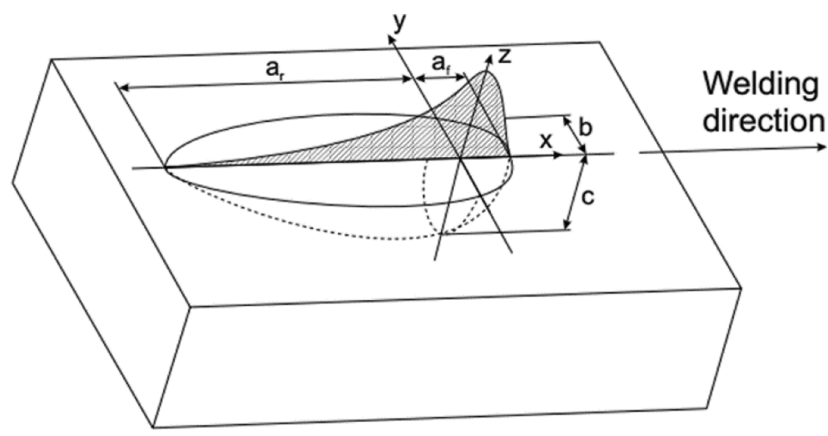

Figure 4: Double ellipsoid heat source [12].

$$
q(x, y, z, t)=\frac{6 \sqrt{3} f_{r} Q}{a_{r} b c \pi \sqrt{\pi}} e^{-3 x^{2} / a_{r}^{2}} e^{-3 y^{2} / b^{2}} e^{-3[z+v(\tau-t)]^{2} / c^{2}}
$$

where $a_{f}$ and $a_{r}$ is the rear and front quadrant of the ellipsoidal length respectively, $b$ is the half width of the weld pool, $c$ is the depth of the weld pool, $\tau$ is the lag factor which is needed to define the position when time $t=0, \mathrm{v}$ is the weld speed, $Q$ is the total input energy. This heat source is usually used to simulate the media energy welding process, such as TIG, MIG.

For electron and laser beam welding, the accurately simulation of deep penetration is very important. The temperature field is determined by this parameter. The conical heat source (also named 3D Gaussian) is suggested for high energy welding process [2]. This heat source includes the two parts, i.e., one is the Gaussian

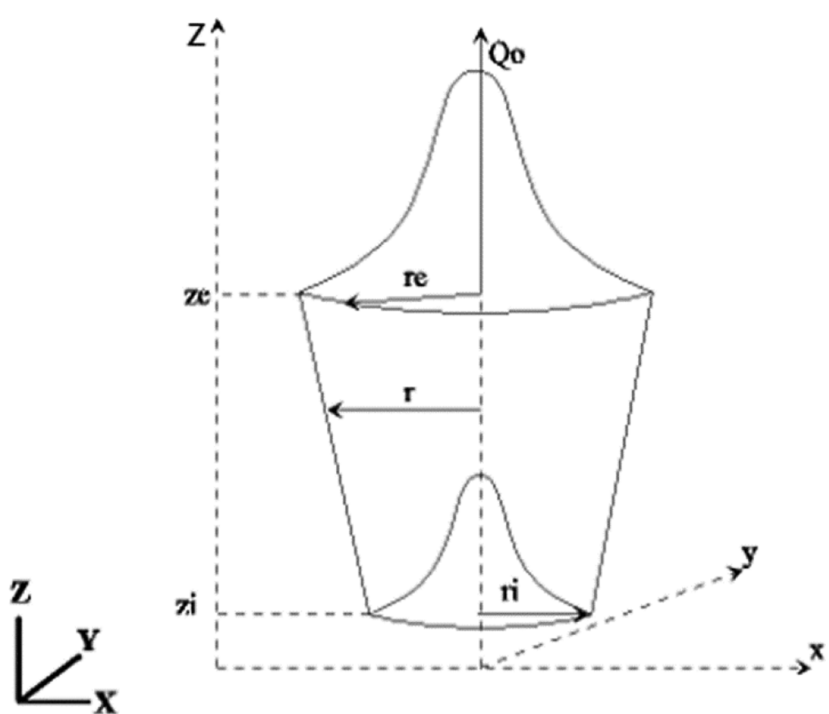

Figure 5: Conical heat source.

distribution radically which can give the good thermal distribution, another is linear distribution axially which can relatively accurate describe the deep penetration during welding simulation, as shown in Figure 5. Heat source distribution is given by the following function:

$$
\begin{gathered}
Q(x, y, z)=Q_{0} \exp \left(-\frac{x^{2}+y^{2}}{r_{0}^{2}(z)}\right) \\
r_{0}(z)=r_{e}+\frac{r_{i}-r_{e}}{z_{i}-z_{e}}\left(z-z_{e}\right)
\end{gathered}
$$

where $Q_{0}$ is the maximum input energy density, $x, y, z$ and $r$ is the conical geometry parameters.

Furthermore, LUNDBÄCK A [12] used the combined double-ellipsoid and conical heat sources to simulate the EBW or laser welding processes. However, this method is very complex and compute cost is very huge, it is not usually used.

\section{Heat transfer model}

When welding or heat treatment, the heat is transferred throughout the rest of the work plates by conduction and radiation, which leads to cool to the room temperature. Thus, this is also the weld or heat treatment thermal boundary conditions.

The convection is defined here via the following equation:

$$
q_{k}=\alpha_{k} \Delta T
$$


where, $\alpha_{k}$ is the convection coefficient which is taken to be $25 \mathrm{~W} / \mathrm{m}^{2}, \Delta T$ is the temperature difference between environment and plates.

The radioactive is expressed here by the following equation:

$$
q_{r}=\varepsilon c_{0} T^{4}
$$

where $\varepsilon$ is the blackness coefficient, Tis the work plate absolute temperature, $c_{0}$ is the Stefan-Boltzmann coefficient $\left(5.67 \times 10^{-8}\left(\mathrm{~W} / \mathrm{m}^{2} \mathrm{~K}\right)\right)$, the constant emissivity value is set to 0.8 .

During heat transfer analysis for welding and heat treatment, temperature-dependent thermal material properties, such as thermal conductivity and specific heat, were employed. Meanwhile, temperature-dependent mechanical properties such as thermal strains and yield stress also were used to solve the stress and strain.

\section{Mechanical phenomena}

During welding and heat treatment, the total strain rate $\dot{\varepsilon}_{i j}^{T o t}$ in Thermal-elastic-plastic constitutive models is subdivided into the elastic $\dot{\varepsilon}_{i j}^{e}$, plastic $\dot{\varepsilon}_{i j}^{p}$ due to rate independent plasticity, thermal $\dot{\varepsilon}_{i j}^{\text {th }}$ including thermal expansion and creep strain rate $\dot{\varepsilon}_{i j}^{c}$, volume change strain rate during phase transformations $\dot{\varepsilon}_{i j}^{T v}$ and transformation plasticity strain rate $\dot{\varepsilon}_{i j}^{T r p}$. This can be expressed by:

$$
\dot{\varepsilon}_{i j}^{T o t}=\dot{\varepsilon}_{i j}^{e}+\dot{\varepsilon}_{i j}^{p}+\dot{\varepsilon}_{i j}^{t h}+\dot{\varepsilon}_{i j}^{c}+\dot{\varepsilon}_{i j}^{T r v}+\dot{\varepsilon}_{i j}^{T r p}
$$

Due to no solid phase transformation occur during welding and heat treatment of nickel alloy, transformation strain rate including volume change and plasticity are not accounted for this simulation. Meanwhile, creep is assumed to occur during the holding of heat treatment process which the creep strain rate is very low. So, the expression is:

$$
\dot{\varepsilon}_{i j}^{T o t}=\dot{\varepsilon}_{i j}^{e}+\dot{\varepsilon}_{i j}^{p}+\dot{\varepsilon}_{i j}^{t h}+\dot{\varepsilon}_{i j}^{c}
$$

And during welding process, it should know that no creep strains occur because of very short hold time at high temperature. The strain expression of welding is:

$$
\dot{\varepsilon}_{i j}^{T o t}=\dot{\varepsilon}_{i j}^{e}+\dot{\varepsilon}_{i j}^{p}+\dot{\varepsilon}_{i j}^{t h}
$$

Meanwhile, during PWHT process, the creep strain rate is suggested by the Norton's law [13, 14].

$$
\dot{\varepsilon}_{i j}^{c}=\mathrm{k} \sigma^{-n} S_{i j}
$$

where $\dot{\varepsilon}_{i j}^{c}$ is the creep strain rate, $\sigma^{-n}$ is the equivalent stress and $S_{i j}$ is the deviatoric stress. The material parameters, $\mathrm{k}$ and $\mathrm{n}$ can be obtained directly from stress relaxation test at the desired temperature.

\section{Numerical model}

Base material is polycrystalline nickel alloy GH80A (International named Nimonic 80A). The microstructures of this alloy is face-cantered cubic (FCC). The material includes two phases, one is the base phase (y), another is strength phase $\left(y^{\prime}\right)$. In the solid state, there is no phase transition. This alloy has good weld ability, which the electron beam welding can produce defect-free welds with this alloy [15]. The microstructure is presented by Figure 6 . The chemical compositions of alloy are listed in Tables 1.

In order to accurately get the temperature and residual stress/strains in the EBW and post welding heat treatment, 3D finite element numerical model must be

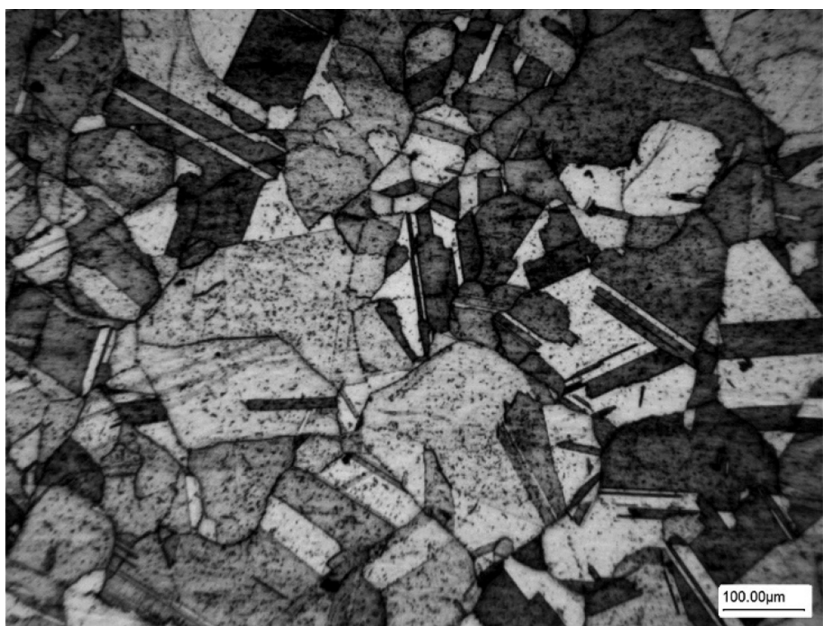

Figure 6: Microstructure of GH80A.

Table 1: Chemical compositions of GH80A (mass. \%).

\begin{tabular}{lllll}
\hline $\mathrm{C}$ & $\mathrm{Cr}$ & $\mathrm{Al}$ & $\mathrm{Ti}$ & $\mathrm{Ni}$ \\
\hline $0.04-0.10$ & $18.0-21.0$ & $1.00-1.80$ & $1.8-2.7$ & $\mathrm{Bal}$ \\
\hline
\end{tabular}

considered. The position of welding seam is located at the center of plate, as shown in Figure 7.

During welding simulation, the temperature fields are computed firstly by the heat source and material thermal properties, then the stress- and strain-dependent elastic and plastic 


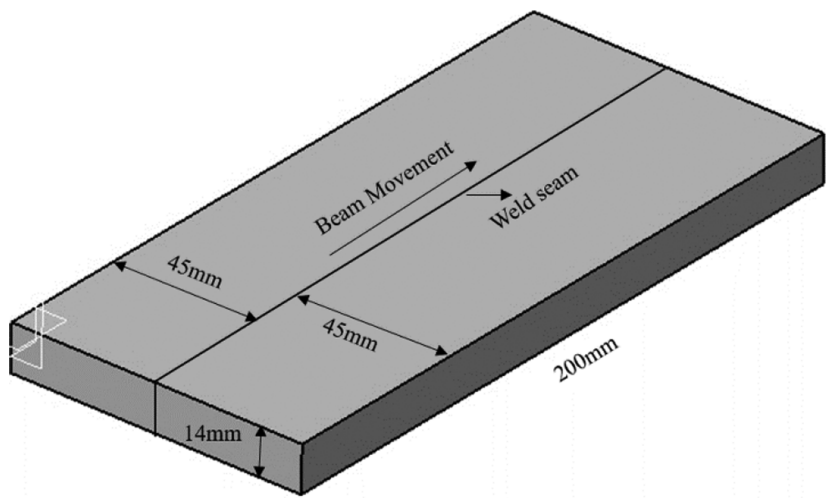

Figure 7: Butt welding plates.

is calculated which temperature history is employed as the thermal boundary condition. The material properties dependent temperature is used from literature [16]. The materials parameters are extrapolated linearly with temperature used Origin software if the needed temperature is higher than offered from literatures [17]. The detail material properties are presented in Table 2. And Poisson's ratio is 0.31 and density is $8150 \mathrm{~kg} / \mathrm{m}^{3}$.

\section{Results and discussion}

\section{Thermal analysis}

The predicted thermal analysis results including welding joints shape and temperature field which were obtained during the welding process. Figures $8(\mathrm{a})$ and $8(\mathrm{~b})$ show the actual experiment EBW joints shape and predicted joint shape respectively. The yellow joint shape in Figure $8(\mathrm{~b})$ is

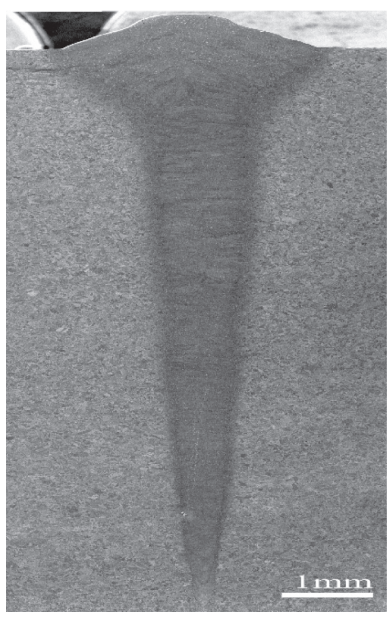

(a) Experiment joint shape

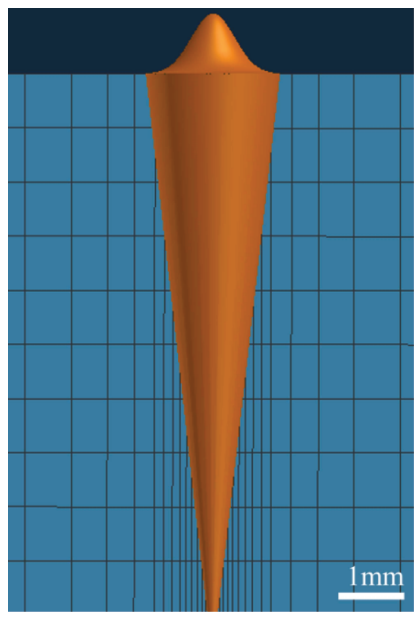

(b) Predicted joint shape
Figure 8: EBW joint shape.

fitted with the conical heat source (see Figure 5) model. The top and down diameter of predicted joint shape is determined by the actual EBW joint geometry parameters. Figure 9 is the simulation and experimental result of welding joint. The size of HAZ is very small. It is the good match in deep penetration direction comparing the experiment and simulation welding joint shape.

Figure 10(a) shows temperature as function of time at different depth points in the heat area zone (HAZ). The maximum temperature is about $2700^{\circ} \mathrm{C}$. With increase of the depth, top temperature quickly decreases. All the points temperature arrives $300^{\circ} \mathrm{C}$ at $25 \mathrm{~s}$, then to linearly decreases. Figure 10(b) shows temperature as function of time at same depth position and different distance from the heat source in the normal direction. With increase of the distance from the heat source, top temperature

Table 2: Material properties of GH80A.

\begin{tabular}{lrrrrr}
\hline Temperature $\left({ }^{\circ} \mathrm{C}\right)$ & $\begin{array}{r}\text { Young's } \\
\text { Modulus(GPa) }\end{array}$ & $\begin{array}{r}\text { Yield } \\
\text { stress } \\
(\mathbf{M P a})\end{array}$ & $\begin{array}{r}\text { Thermal } \\
\text { conductivity } \\
(\mathbf{W} / \mathbf{m} * \mathbf{K})\end{array}$ & $\begin{array}{r}\text { Specific heat } \\
\left.\mathbf{J} / \mathbf{g}^{\star} \mathrm{K}\right)\end{array}$ & $\begin{array}{r}\text { Linear } \\
\text { expansion } \\
\left(\mathbf{1 0}^{-6} \mathrm{C}^{-1}\right)\end{array}$ \\
\hline 20 & 222 & 980 & 11.55 & 0.44 & 12.18 \\
100 & 218 & 991.1 & 12.78 & 0.46 & 12.18 \\
200 & 214 & 970.2 & 14.4 & 0.48 & 12.86 \\
300 & 206 & 952.5 & 15.9 & 0.49 & 13.69 \\
400 & 200 & 935.9 & 17.5 & 0.51 & 14.08 \\
500 & 194 & 919.6 & 19.0 & 0.53 & 14.50 \\
600 & 189 & 903.2 & 20.52 & 0.55 & 14.94 \\
700 & 179 & 886.3 & 22.04 & 0.64 & 15.36 \\
900 & 145.7 & 360.6 & 25.84 & 0.82 & 16.47 \\
1100 & 125.8 & 44.0 & 29.28 & 0.67 & 17.47 \\
1200 & 115.8 & 24.6 & 30.85 & 0.69 & 17.97 \\
1300 & 105.9 & 14.3 & 32.50 & 0.68 & 18.47 \\
\hline
\end{tabular}




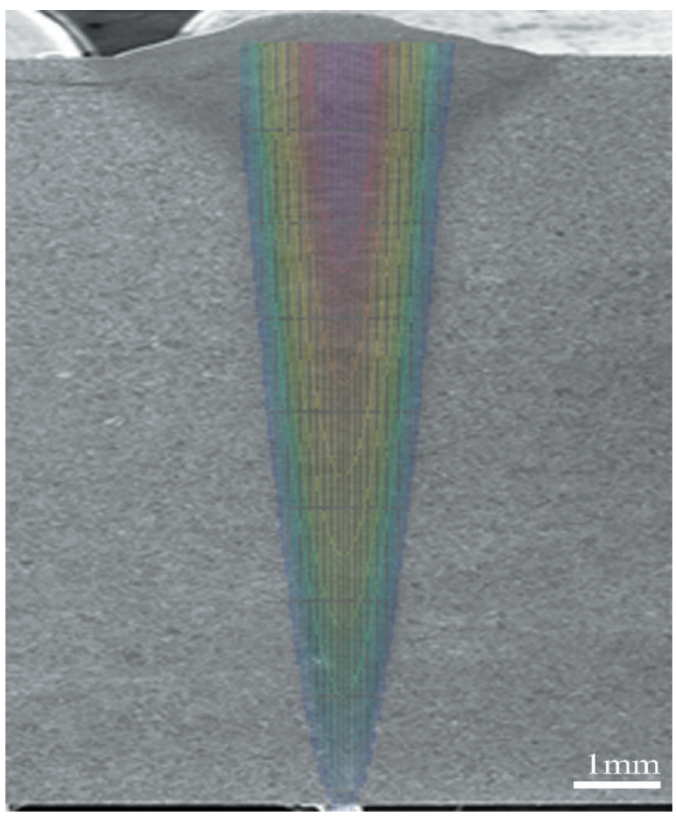

Figure 9: Simulation and experimental results of welding joint.

quickly decreases. All the points temperature arrives $150^{\circ} \mathrm{C}$ at $70 \mathrm{~s}$ and tends to stabilizes.

\section{Welding residual stress analysis}

Thermo-mechanical coupled analysis was used to compute the thermal stresses during welding and post welding heat treatment. Considering the temperaturedependent material property method [17], the local and transient heating and global cooling during welding lead to unequal thermal conduction and expansion, after cooling which will finally produce the residual stress and deformation. Meanwhile, heating and cooling during
PWHT also leads to residual stress and deformation, the change of value is more stabilization than welding.

Figure 11(a) shows the longitudinal stress along welding direction on the top surface. The stress is the minimum and the value is about $-150 \mathrm{MPa}$ near the HAZ which means the pressure stress, with increase of the distance from welding lines, the stress develops in the plus and the value change to $100 \mathrm{MPa}$ which indicates the pull stress. And Figure 11(b) shows the transverse stress vertical welding direction on the top surface. The stress in weld beam and near the HAZ is the plus and the value is about $-30 \mathrm{MPa}$, with increase of the distance from welding lines, the stress develops to increase and the value is about $36 \mathrm{MPa}$ which means the pull stress.

\section{Post welding heat treatment residual stress analysis}

After welding and cooling to room temperature, the plate was heating up to $700^{\circ} \mathrm{C}$ within $40 \mathrm{~min}$, and holding 60 min, finally furnace cooling, the heat treatment curve is showed in Figure 2. The stress from welding and cooling at room temperature acts as the initial stress conditions in order to couple the post welding heat treatment. Figure 12 shows the Von Mises stress distribution with different time.

The value of stress from welding at the end of cooling at room temperature is about $310 \mathrm{MPa}$ in Figure 12(a), which is mainly distributed along the weld seam and HAZ and is the initial stress for the post welding heat treatment. The maximum Von Mises stress is located in the center of weld seam. The stress decreases quickly as the temperature increases. The Von Mises stress was released from 310 to $150 \mathrm{MPa}$ during $1 \mathrm{~h}$
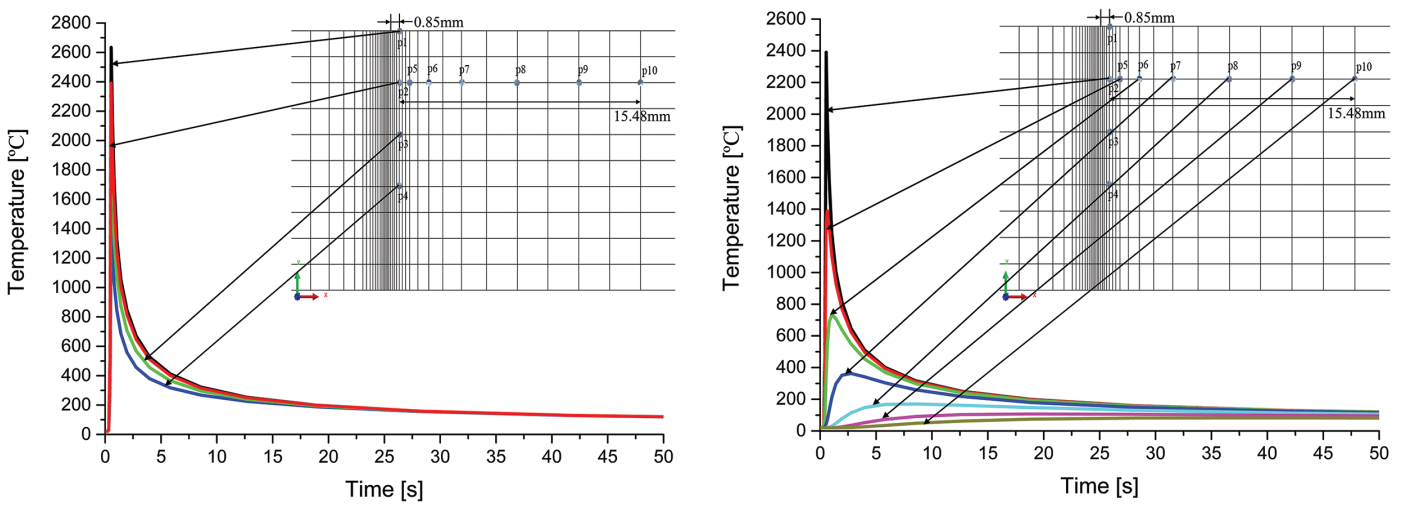

Figure 10:

Temperature vs time curve, (a) for different depth points and (b) for same depth of different points. 


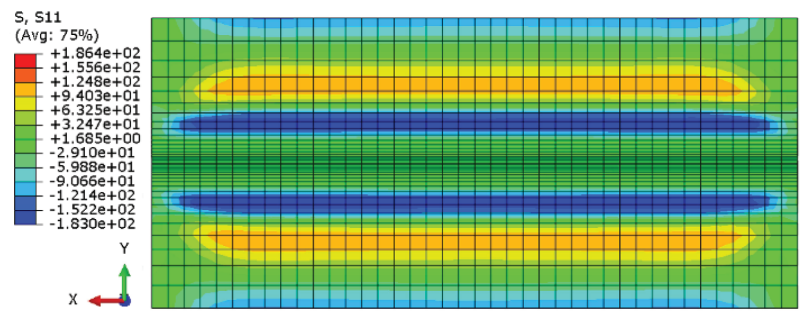

(a) Longitudinal stress along welding direction

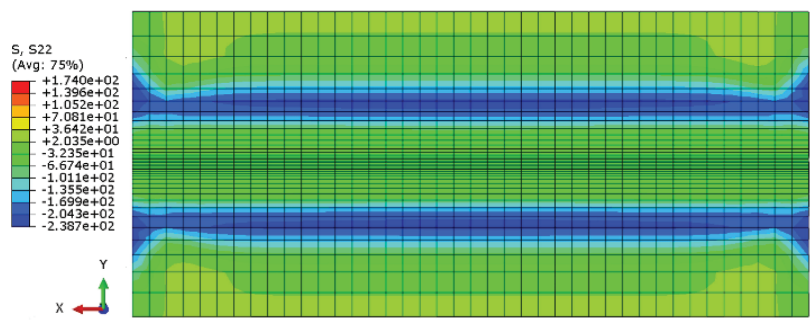

(b) Transverse stress vertical welding direction

Figure 11: Welding stress distribution.

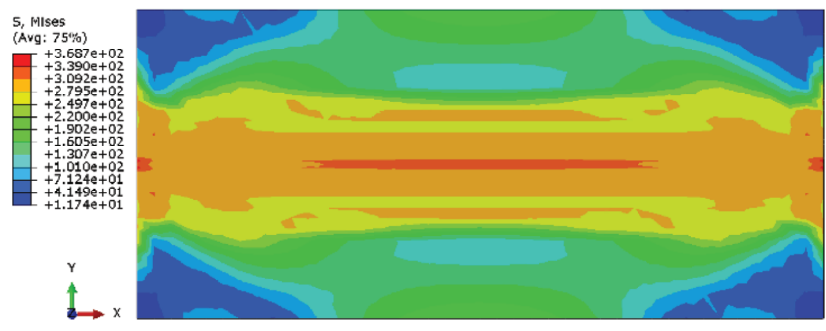

(a) Von Mises stress after weld cooling

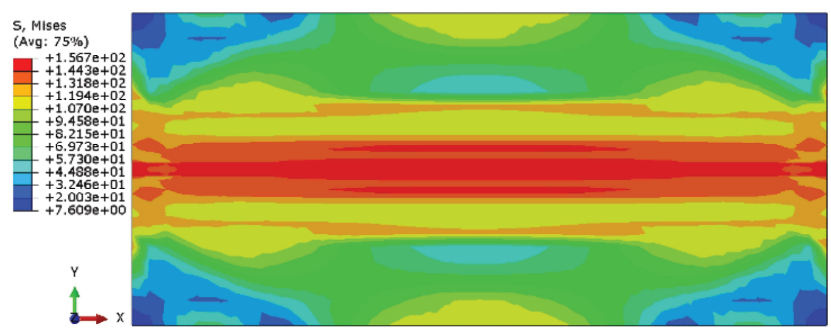

(b) Von Mises stress after holding

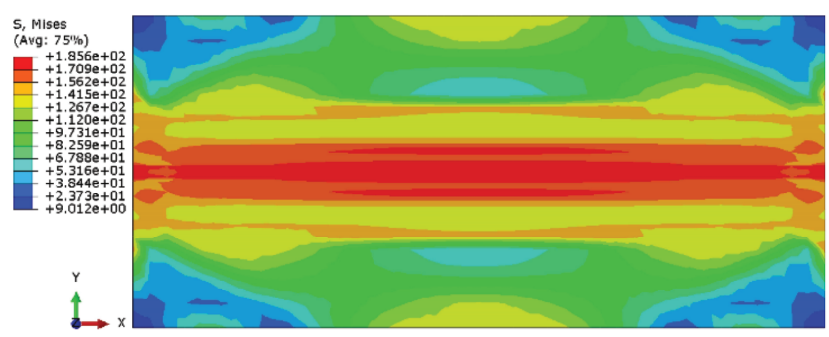

(c) Von Mises stress after PWHT cooling

Figure 12: Von Mises stress with the different time. holding period in Figure 12(b), which shows that Von Mises stress distributes along the weld seam and HAZ. And stress also decreases in these positions. This means PWHT process is very useful to decrease the stress located in weld seam and HAZ. After furnace cooling, the value of Von Mises stress is up to $170 \mathrm{MPa}$, as shown in Figure 12(c), which has the same distribution with the Figure 12(b). At the end of the furnace cooling, the stress is increased slightly about $20 \mathrm{MPa}$ than the holding stage.

\section{Conclusions}

The electron beam welding and post welding heat treatment coupling simulation of GH80A plates was successfully performed using ABAQUS. The coupling approach understands the optimization of the total chain of material manufacturing processes instead of the processes individually. The computed results including thermal history, residual stress and displacement and stress relaxation during welding and post welding heat treatment. Several conclusions can be obtained as follow:

(1) In order to get more accurate results, the 3D model of the welding and post welding heat treatment process should be used. The heat source model should be chosen the 3D Gaussian, which can consider the deep penetration of welding beam molten. This is very important for accuracy of results. Compared with the actual welding joint sharp, there is a satisfactory agreement.

(2) Temperature dependent material properties are very important during welding and HT. For the high temperature, a linear function with the temperature from room temperature is used. The welding temperature is computed and validated in this article.

(3) In order to consider the actual welding and post welding heat treatment processes and get accurate results, the combined welding and post welding heat treatment process simulation is necessary. With the help of coupling numerical model, the welding residual stress can act as the initial stress state for post welding heat treatment. The residual stress release from welding to PWHT is computed and compared. This is the key parameter for coupling process to optimize the PWHT process. 
Funding: This work was supported by the National Natural Science Research Foundation of China (11327801, 11502151 and 11572057), the Program for Changjiang Scholars and Innovative Research Team (IRT14R37), and Key Science and Technology Support Program of Sichuan Province (2015JPT0001).

\section{References}

[1] M.S. Węglowski and S. Błacha, Vacuum., 130 (2016) 72-92.

[2] J.A. Goldak and M. Akhlaghi, Computational Welding Mechanics, Springer, New York (2005).

[3] J. Mackerle, Comp Mater Sci., 27 (2003) 313-332.

[4] P. Lacki and K. Adamus, Comput Struct., 89 (2011) 977-985.

[5] P.H. Chang and T.L. Teng, Comp Mater Sci., 29 (2004) 511-522.

[6] X. Yang, J. Zhu, Z. Nong, Z. Lai and D. He, Comp Mater Sci., 69 (2013) 396-413.

[7] D. Berglund, H. Alberg and H. Runnemalm, Finite Elem Des., 39 (2003) 865-881.
[8] D. Rosenthal, Trans. ASME, 68(1946) 849-865.

[9] R.R. Rykalin, Weld World., 12 (1974) 227-248.

[10] V P, R T, A U, Myers, Welding Journal, 48(1969) 295-305.

[11] J. Goldak, A. Chakravarti and M. Bibby, Mta, 15B (1984) 299-305.

[12] A. Lundbäck, Finite Element Modelling and Simulation of Welding of Aerospace Components, Lulea University of Technology, Lulea, Sweden. (2003).

[13] H. Serizawa, S. Nakamura, H. Tanigawa, H. Ogiwara and H. Murakawa, J Nucl Mater., 442 (2013) 535-540.

[14] D.C. Stouffer and L.T. Dame, Inelastic Deformations of Metals: Models, Mechanical Properties and Metallurgy, John Wiley and Sons Ltd, New York (1996).

[15] J.N. DuPont, J.C. Lippold and S.D. Kiser, Welding Metallurgy and Weldability of Nickel-Base Alloys, John Wiley \& Sons Inc., New Jersey (2009).

[16] China Aeronautical Materials handbook(Second Volume) Wrought Superalloy and Cast Superalloy, China Aeronautical Materials Handbook Editorial Board, China Standard Press, Beijing (2002).

[17] X. Zhu and Y. Chao, Comput Struct., 80 (2002) 967-976. 